\title{
METHANOL PRODUCTION FROM STEEL-WORK OFF-GASES AND BIOMASS BASED SYNTHESIS GAS
}

\author{
T. Ekbom ${ }^{1}$, C. Hulteberg ${ }^{2,3}$, C-E Grip ${ }^{4}$, M. Larsson ${ }^{5}$, J. Lundgren ${ }^{4}$, L. Nilsson ${ }^{6}$, P. Tunä ${ }^{3}$ \\ ${ }^{1}$ Grontmij AB, Stockholm, Sweden ${ }^{2}$ Nordlight AB, Limhamn, Sweden ${ }^{3}$ Lund University, Sweden ${ }^{4}$ Luleå University of Technology, \\ Sweden ${ }^{5}$ Swerea MEFOS AB, Sweden ${ }^{6}$ SSAB EMEA, Sweden \\ joakim@ltu.se \\ +46920491307
}

\begin{abstract}
The main objective has been to describe different cases of the methanol production from steel-work off gases (Coke oven gas and Basic oxygen furnace gas) and biomass based synthesis gas. The SSAB steel mill in the town of Luleå, Sweden has been used as a basis to analyze four different methanol production cases.

The studied biomass gasification technology is based on a fluidized bed gasifier unit, where the production capacity is determined from case to case coupled to the heat production required to satisfy the local district heating demand. Critical factors are the integration of the gases with availability to the synthesis unit, to balance the steam system of the biorefinery and to meet the district heat demand of Luleå.

For each case, the annual production potential of methanol, the overall production efficiencies and the effects on the total steel plant have been estimated.
\end{abstract}

Keywords: methanol production, coke-oven gas, biomass gasification, steel mill

\section{NONMENCLATURE}

Abbreviations

COG Coke Oven gas

BOFG Basic Oxygen Furnace gas

BFG Blast Furnace gas

LHV Lower Heating Value

$\mathrm{MeOH} \quad$ Methanol

EAF Electric Arc Furnace

CHP Combined Heat and Power

$\mathrm{PI} \quad$ Process Integration

$\mathrm{DH} \quad$ District Heating

BP Back Pressure

HP High Pressure

LP Low Pressure

\section{INTRODUCTION}

There are two major global steel production routes, the EAF steelmaking and BF/BOF based steelmaking, where approximately $1 / 3$ of the global steel production is scrap based (EAF steelmaking) and $2 / 3$ is based on virgin raw materials via the integrated steelmaking route (BF/BOF).

An integrated steel plant often consists of various process units, such as coking plant (CP), blast furnace (BF), basic oxygen furnace (BOF), secondary metallurgy, continuous casting, and rolling mill. Most plants also have some auxiliary units on site, for instance, lime kiln, oxygen plant and sinter plant. There are process gases generated from the process units of $\mathrm{CP}, \mathrm{BF}$ and $\mathrm{BOF}$ i.e. coke oven gas (COG), blast furnace gas (BFG) and basic oxygen furnace gas (BOFG). Typical chemical compositions of the gases are shown in Table 1.

Table 1. Composition of the steel-work off gases (Vol\% db)

\begin{tabular}{l|c|c|c}
\hline Compounds & COG & BFG & BOFG \\
\hline $\mathrm{H}_{2}$ & 63 & 3 & 4 \\
\hline $\mathrm{CO}$ & 6 & 20 & 57 \\
\hline $\mathrm{CH}_{4}$ & 22 & 0 & 0 \\
\hline $\mathrm{C}_{2} \mathrm{H}_{6}$ & 3 & 0 & 0 \\
\hline $\mathrm{CO}_{2}$ & 2 & 24 & 24 \\
\hline $\mathrm{N}_{2}$ & 4 & 53 & 15 \\
\hline $\mathrm{LHV}\left(\mathrm{MJ} / \mathrm{Nm}^{3}\right)$ & 17.5 & 2.85 & 7.6 \\
\hline
\end{tabular}

The gases are generally used as fuel in different process units within the plant. It is also quite common to have a power plant or combined heat and power plant at the site to utilize the process gases for production of power, process steam and/or heat, which are used internally within the plant and sometimes also for external users in the community. Thus, the energy system for the integrated steel plant is large and complicated.

The analysed steel plant applies the BF/BOF-based steel production route using agglomerated iron ore (pellet) as the main source of iron to produce primary steel. The use of coke in the BF/BOF route is necessary making the coke plant of vital importance for the production system. In the $\mathrm{CP}$, coke is produced by dry distillation of cooking coals, resulting in dense char agglomerates. The coke oven gas is the cleaned raw gas formed during the dry distillation when volatiles from the coals are released. In the raw gas cleaning, tar, sulphur and benzene are removed. In the BF 
iron ore pellets are reduced and melted. Coke and injected pulverized coal $(\mathrm{PCl})$ are used as reductants. The carbon rich liquid iron from the BF process is converted to steel in the oxygen steelmaking process by blowing oxygen onto the bath oxidizing the carbon. As additional iron carrier and coolant in the converter process, steel scrap and iron ore pellets are used. The liquid steel is finalised in the secondary steelmaking processes and finally casted in two continuous casters. In the studied system the rolling mill, which usually is within the site, is located at another site (located in another geographical region). The surplus of process gases are therefore used in a combined heat and power plant.

The process gases have different availability and energy density. The COG has a high heating value (typical LHV 17$18 \mathrm{MJ} / \mathrm{Nm}^{3}$ ) and is also rich on hydrogen ( 60 vol\%). The BOFG has a heating value in the range of $6-8 \mathrm{MJ} / \mathrm{Nm}^{3}$ and is rich in carbon monoxide ( $60 \mathrm{vol} \%$ ). It is of great interest to find ways to utilize the excess gases for the production of higher value products, e.g automotive fuels and/or chemicals instead of production of heat and power.

Commercial technology to produce methanol from COG already exists and is in particular progress in China. In 2009, China had a production capacity of approximately 27 million tonnes of methanol per year, of which COG to methanol accounted for $15 \%$ [1].

There are also possibilities to introduce biomass via gasification to increase the production and to reduce the specific $\mathrm{CO}_{2}$ emissions of the product. This is of particular interest in Scandinavia, which has several steel industries and abundant resources of biomass. Preliminary and more general investigations regarding involvement of biomass in COG based methanol production has previously been published by the authors [2].

The SSAB EMEA steel plant in the town of Luleå, Sweden has been used as case basis. The steel plant is based on the $\mathrm{BF} / \mathrm{BOF}$ route. The blast furnace (BF) is operated with $100 \%$ pellets, and is equipped with pulverized coal injection $(\mathrm{PCl})$, normally $149 \mathrm{~kg} / \mathrm{t} \mathrm{HM}$ (tonne hot metal). The CP produces the majority of the coke used in the BF. There are two basic oxygen furnaces (BOF converters) in the system, operated with hot metal from the BF and a small amount of scrap. The crude steel is further treated in the alloying processes, CASOB and the RH-vacuum oven. The steel making is followed by two continuous casters. The slabs are transported $1000 \mathrm{~km}$ by train to the rolling mill located in Borlänge. The steel work gases are used internally as primary fuel; the $C P$ is under-fired with pure COG, and the hot stoves for the BF are fired with a mixture of BFG and COG. The COG is also used as fuel in various burners at the steel plant as well as for primary fuel in a steam boiler and in a lime furnace. Since the rolling mill is located at another geographical location, a surplus of process gases arises. The surplus is therefore used as primary fuel in a combined heat and power plant (CHP), producing steam, heat and electricity. The produced power is used within the steel plant system and the heat covers a main part of the annual heat demand of the community. Drying gas from the power plant is also delivered to a nearby wood-pellet plant.

The main objective of this work has been to describe different cases of the methanol production from steel-work off gases (COG and BOFG) and biomass based synthesis gas. Four different methanol production schemes with the following feedstock's have been analyzed:

- The excess COG and $40 \%$ of the available BOFG

- The excess COG mixed with biomass synthesis gas

- $\quad$ The excess COG, BOFG and biomass synthesis gas

- Hydrogen (extracted from the COG via Pressure Swing Absorption) mixed with biomass based synthesis gas

For each case, the annual production potential of methanol, the overall production efficiencies and the effects on the total steel plant have been estimated.

\section{MATERIAL AND METHODS}

An overall process integration model of the steel plant has been used to study the integration of a biomass gasifier, syngas conditioning and a methanol synthesis unit into the plant in order to evaluate the effects on the total energy system. The most important modeling constraints are that the process steam balance and production of district heating are maintained.

The modeling approach has been an iterative process between the overall process integration model and the detailed process models of the biomass gasification unit, the syngas conditioning and methanol synthesis.

\subsection{THE PROCESS INTEGRATION MODEL}

The model is based on mathematical programming, i.e. mixed integer linear programming (MILP) and a commercial solver CPLEX has been used. The model structure is represented as a network of nodes and branches, which represent process units and energy/material flows, respectively. The different nodes are connected depending on the input and output to/from each process unit. Each node contains linear equations to express the energy and mass balance required in the process unit. Thus an entire energy system is created. 
The current model is based on a previous model version designed for the SSAB EMEA plant [3]. The different processes included and the main process flows in the model are shown in Figure 1 and 2. The model core is an overall mass- and energy balance for the production chain and separate sub-balances for the main processes which makes it possible to perform a total analysis for the steel plant and to assess the effect of a change in the operation practice for the different processes. In this work, the modeling system has been extended to include a methanol synthesis unit utilizing the excess of off-gases in some cases combined with synthesis gas produced via biomass gasification.

The process integration model provides the possibility to evaluate the different integration possibilities and the effect on the total energy system.

An annual steel production level corresponding to 2.1 Mton of steel slabs has been chosen. Different possibilities to increase or decrease the gas generation has been included in the overall optimization model. Possibilities to increase the available COG through e.g. increased oxygen utilization in the BF hot stoves [4] and alternative prioritization of the generated COG have been assessed. The effect of changing the BF operation practice through changes in the operation practice e.g. $\mathrm{PCl}$ injection rate has also been considered.

The combined heat and power plant produces electricity, steam for wood drying and district heating. There are large seasonal variations of the district heat load for the municipality. The heat load capacity has a peak of 220 $\mathrm{MW}_{\text {th }}$ during winter and a low of just $20 \mathrm{MW}_{\text {th }}$ during summer.

\subsection{THE BIOMASS GASIFIER MODEL}

The model is based on pressurized, oxygen-blown bubbling fluidized-bed gasification technology, which has been scaled to suit the cases. The benefits include fuel flexibility and high cold gas efficiency. The drawbacks are need for tar and methane reforming. Therefore, a reformer has been included and raw gas cleaning with hot gas cyclone and filter and water scrubber. Also the gas is cooled from about $900^{\circ} \mathrm{C}$ producing high pressure steam. The product is a reformed gas which is cooled and cleaned from most alkali, ammonia, chlorides, metals, tars and particles. The model is based on budget quotations from suppliers which have been integrated also for the steam diagram to complete the material and energy balances, as further described in the BioMeeT II report. [5]

\subsection{MODELING GAS CLEANING AND CONDITIONING}

After gasification, the gas is passed through a number of unit operations aiming at purifying and conditioning it. Initially, the temperature of the gas is lowered to $400^{\circ} \mathrm{C}$ to allow for filtration. After filtration the tar content of the gas is removed and any methane in the gas is reacted in a reforming step with oxygen addition [6]. In cases $B$ and $C$, the COG and COG with BOFG is mixed into the biomassgenerated gas upstream of the reforming step. The gases are cooled and the high-quality heat is used for steam generation. Thereafter the gases are controlled to the desired set-point in producing methanol, a $\mathrm{CO}: \mathrm{H}_{2}$-ratio slightly above 2 , using a water-gas shift reactor. This shift is operated as a high-temperature water-gas shift reactor. To control the ratio, the gases are split and one stream is passed through the reactor, shifting it to equilibrium whilst the other stream is bypassed [7]. The residual heat is used for steam and district heat generation upon cooling for a Rectisol ${ }^{\circledR} \mathrm{CO}_{2}$ removal.

The Aspen Plus model consists of the most important unit operations. The reformer is modeled as an adiabatic reactor that minimizes the Gibbs free energy. The conversion of methane and lower hydrocarbons is high under the simulated conditions. Following the reformer is a water gas shift reactor. This reactor is modeled as an adiabatic equilibrium reactor. After the shift reactor, the gas is cooled down and $\mathrm{CO}_{2}$ is removed in a Rectisol scrubber. A multistage compressor with $70^{\circ} \mathrm{C}$ inter cooling is used to compress the synthesis gas to 100 bar prior to

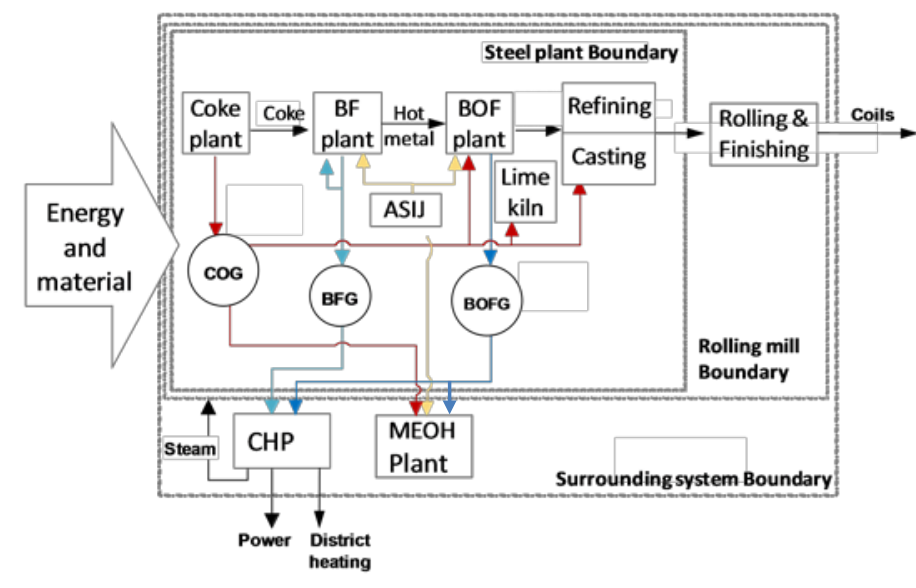

a. Case A : Mix of COG and BOFG

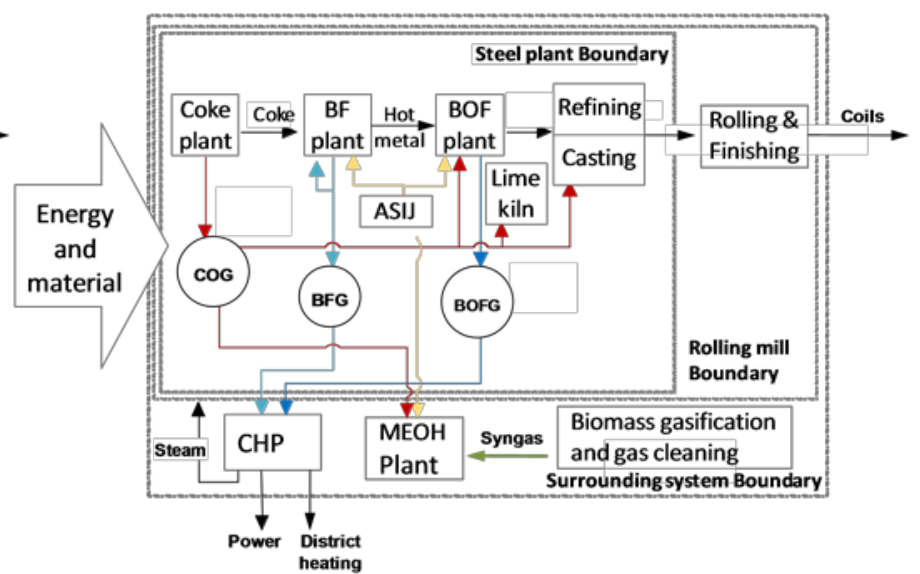

b. Case B. Combined use of COG and biomass based synthesis gas

Figure 1. Schematic descriptions of methanol production cases A and B 


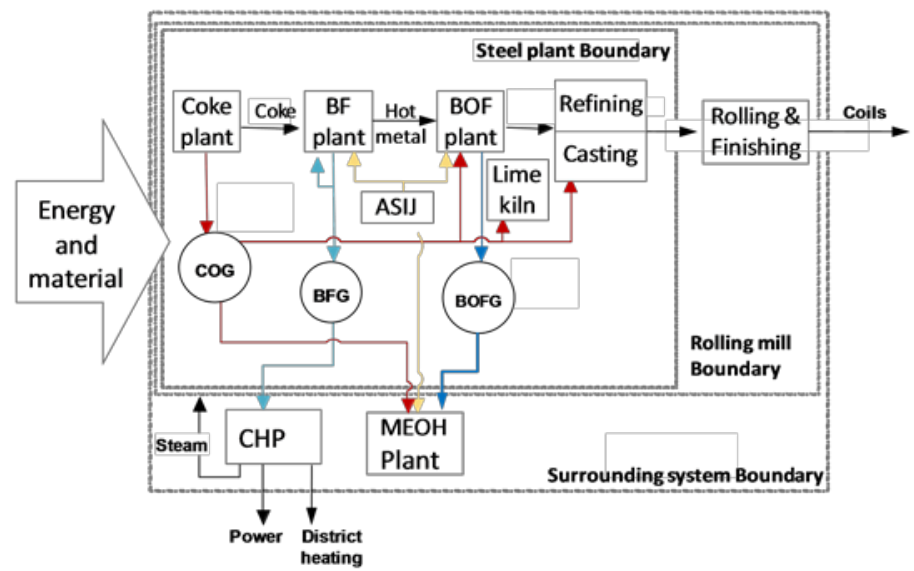

a. Case C :Mix of BOFG, COG and biomass based synthesis gas

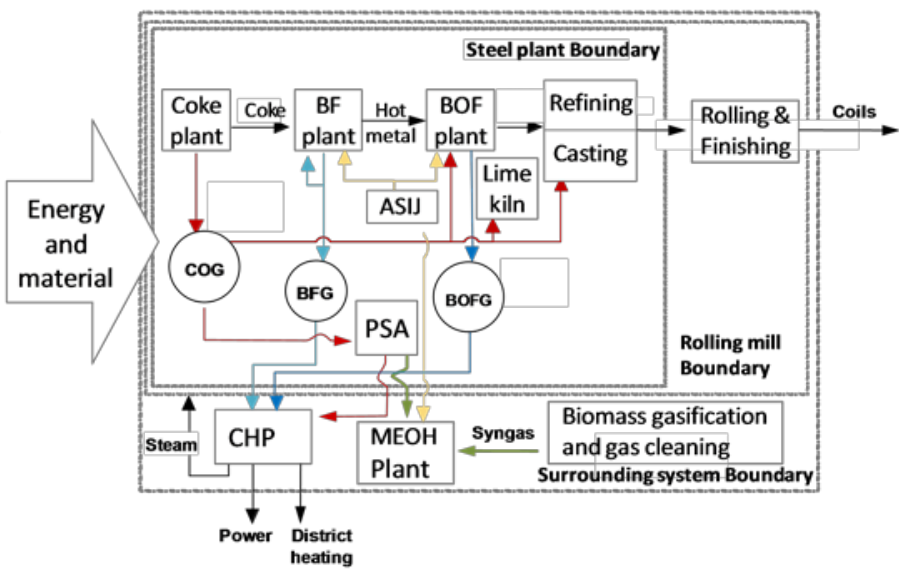

b. Case D. Combined use of extracted $\mathrm{H}_{2}$ from COG and biomass based synthesis gas

Figure 2. Schematic descriptions of methanol production cases $C$ and D

the methanol synthesis reactor. The recycle ratio is set to 4:1. A second compressor is used for the recycled gas. The methanol reactor is modeled as an adiabatic equilibrium reactor. Heaters/coolers are used wherever necessary.

The methanol synthesis is traditionally performed in a packed-bed catalytic reactor operating at elevated pressure. The catalyst used is most commonly based on copper and aluminum oxides [8]. Due to equilibrium reasons, unreacted feedstock is recycled for economic reasons. For the purpose of this simulation, the reaction has been performed at 100 bar pressure and the recycle is set to 3 , with a reactor pressure drop of 8 bar. The reactor operates adiabatically with a temperature increase of $210^{\circ} \mathrm{C}$. After passing through the reactor, the gas stream is cooled to condense the formed methanol and the noncondensable gas is recycled; part of the recycle is bled off to avoid accumulation of contaminants. The condensed methanol is further purified via distillation in two columns, where it is further separated from water and other trace impurities. The methanol production is accompanied by production of other types of energy carriers as well, more specifically high-pressure steam (86 bar $\left.300^{\circ} \mathrm{C}\right)$, lowpressure steam 15 bar $200^{\circ} \mathrm{C}$ ) and district heating.

\subsection{CASE DESCRIPTIONS}

Four different cases are evaluated, see Figures 1 and 2. The most critical factors are the integration of the gases with availability to the synthesis unit, to balance the steam system of the biorefinery and to meet the district heat demand of the city.

For each case, the overall efficiency has been assessed. When using mixed energy carriers, efficiency calculations are helpful but not necessarily an appropriate indicator of the "best" system. The electricity equivalents method is therefore used in this paper to represent the overall exergy of the system and they are calculated using power generation efficiencies [9], using the best available technology to the knowledge of the author's, see Table 2. To exemplify, the methanol efficiency would be calculated by first determining the amount of electricity equivalents that are fed to the system, in the form of biomass, steelplant gases and electricity. Thereafter the electricity equivalence number of the methanol is determined and, to yield the efficiency, it is divided with the feed number.

Table 2. Electricity equivalence number for various energy carriers in the system

\begin{tabular}{l|c|c}
\hline Energy Carrier & $\begin{array}{c}\text { Power Generation } \\
\text { Efficiency }\end{array}$ & Refs. \\
\hline Biomass, COG and BOFG & $46.2 \%$ & {$[10]$} \\
\hline Hot water & $10 \%$ & {$[10]$} \\
\hline Methanol & $55.9 \%$ & {$[11]$} \\
\hline
\end{tabular}

\section{CASE A - COG AND BOFG}

In case $A$ the excess COG (656 GWh) and $40 \%$ of the BOFG (185 GWh), totally $847 \mathrm{GWh}$ of gas per year is used for methanol production. Energy flows are illustrated in Figure 1a. The excess COG is made available by introduction of oxygen enrichment of the hot stoves firing liberating COG, further reprioritization among the COG users. The CHP is operated on the excess of the steel plant gases BFG and BOFG. The steam and heat generated from the $\mathrm{MeOH}$ synthesis is integrated with the CHP. The CHP supplies district heat to the community of $753 \mathrm{GWh}$ annually (according to 2006 years level).

\section{CASE B - COG MIXED WITH BIOMASS SYNTHESIS GAS}

In this case, biomass based synthesis gas is mixed with COG as shown in Figure $1 \mathrm{~b}$. The considered biomass gasification technology is based on a fluidized bed gasifier unit, where the production capacity is determined by the heat production required to satisfy the local district heating demand. The CHP is operated on the excess of BFG and BOFG. The steam and heat generated from the $\mathrm{MeOH}$ synthesis and gasifier is integrated with the existing $\mathrm{CHP}$ cycle. 


\section{CASE C - COG, BOFG AND BIOMASS SYNTHESIS GAS}

In case $C$, also the BOFG is utilized for the methanol production. See Figure 2a. The same amount of COG is utilized as in the CASE A and B. Additional BOFG of 492 $\mathrm{GWh}$ is introduced to the $\mathrm{MeOH}$ synthesis together with the biomass based synthesis gas. The CHP is fueled by the BFG. In this operational mode the CHP is operated close to the lower limit of heat value of fuel gas.

\section{CASE D - EXTRACTION OF THE HYDROGEN}

In this case, the hydrogen is separated from the COG and then mixed with the biomass synthesis gas as shown in Figure 2b. Hydrogen is separated from the COG by pressurized swing absorption (PSA) technique. The separated $\mathrm{H}_{2}$ corresponds to $211 \mathrm{GWh}$. The resulting tail gas is fired in the CHP together with BFG and BOFG.

\section{RESULTS}

Case A where the excess COG and $40 \%$ of the BOFG results in the smallest production capacity, 98000 tons per year. The methanol efficiency, on the other hand, becomes the highest exceeding 70\% (calculated on an electricity equivalence basis). In the case with mixing COG into the biomass generated gas before the reformer (Case $\mathrm{B}$ ), the potential production is about 270000 tons of methanol per year but to a significantly lower efficiency, almost 56\%. In case $C$, when COG, BOF and biomass synthesis gas are used, the equivalent figure is 282000 tons per year with a slightly higher efficiency than in Case B, 57\%. In case D 245000 tons of methanol per year are produced, but with the lowest efficiency, only 43\%. As shown in Table 3, the different cases have different outputs of the other energy carriers. When relating them to the produced methanol amount, the differences in steam production are low, and the only major outlier is the district heat production in the A case which is unusually low. This is also mirrored in the high methanol efficiency.

The outputs from the various cases are summarized in Table 3.

Table 3. Steam, district heating and tail gas outputs of the different cases

\begin{tabular}{l|c|c|c|c}
\hline Case & $\begin{array}{c}\text { HP Steam } \\
(\mathrm{kg} / \mathrm{s})\end{array}$ & $\begin{array}{c}\text { LP Steam } \\
(\mathrm{kg} / \mathrm{s})\end{array}$ & $\begin{array}{c}\text { District } \\
\text { heating } \\
(\mathrm{MW})\end{array}$ & $\begin{array}{c}\text { Tail gas } \\
(\mathrm{MW})\end{array}$ \\
\hline $\mathrm{A}$ & 4.7 & 2.7 & 6.7 & 19.5 \\
\hline $\mathrm{B}$ & 22.8 & 9.3 & 73 & 50.9 \\
\hline $\mathrm{C}$ & 27.7 & 11.1 & 75 & 58.2 \\
\hline $\mathrm{D}$ & 20.8 & 9.1 & 69 & 41.9 \\
\hline
\end{tabular}

Figure 3 shows the annual production capacities and the methanol efficiencies of the different cases.

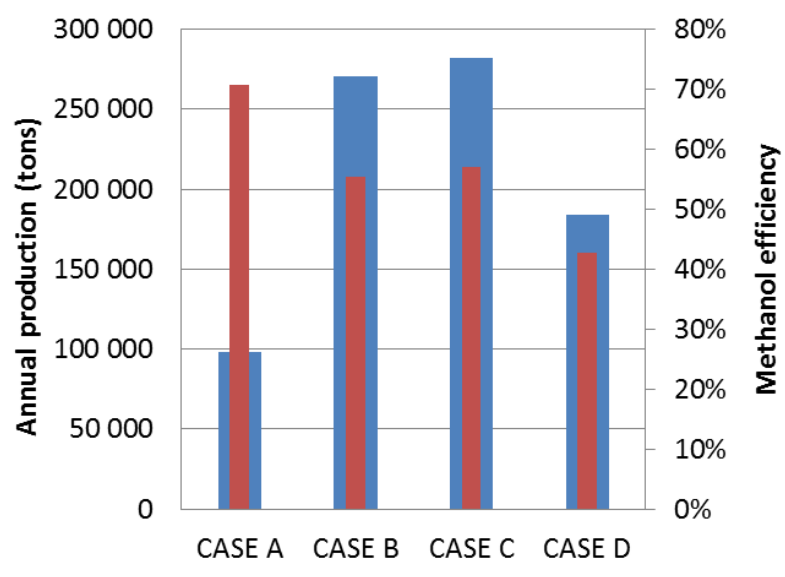

Figure 3. Blue bars show the production capacities and red bars illustrate the methanol production efficiencies

\subsection{TOTAL SITE ANALYSIS}

In case $A$, the total amount of COG made available for methanol production amounts to $656 \mathrm{GWh}$ and BOFG used amounts to $185 \mathrm{GWh}$. This is achieved by utilizing stove oxygen enrichment technology in the firing of the hot stoves which enables the hot stoves to be operated on purely BFG instead of a mixture of BFG and COG. The COG made available amounts to roughly $360 \mathrm{GWh}$ annually. Additional COG and BOFG is made available to methanol production prioritization methanol production over CHP. The total amount of fuel gases to the power plant decrease from $2281 \mathrm{GWh}$ to $2126 \mathrm{GWh}$. The energy in the fuel gases are still enough for $\mathrm{DH}$ production. The total flaring of process gases decreases to $131 \mathrm{GWh}$. The decreased flaring and change in utilization of the fuel gas influences the total energy efficiency of the CHP and the combined efficiency based on methanol, heat and power. The total efficiency increases to $64 \%$ as the increased use of COG in methanol production decreases the flared gas amounts, see Table 4.

In Case B, COG together with synthesis gas from biomass gasification is used for methanol production. In this case significant HP steam is recovered from the methanol production which is integrated into the existing steam cycle at the CHP. The fuel gases supplied to the CHP decreases to $1422 \mathrm{GWh}$, however the energy in the tail gas from the $\mathrm{MeOH}$ synthesis is supplied to the power plant. The recovered HP steam from the synthesis influences the steam cycle of the power plant limiting the amount of fuel gases possible to recover. This results in increased flaring of the steel plant gases. The total efficiency increases to $59 \%$ compared to the reference system. However the flaring increased substantially.

In case C, also 492 GWh of BOFG is introduced in the feedstock for methanol production. In this case the largest amount of HP steam is supplied to the CHP. The effect of utilizing the BOFG in methanol production can be seen on the amount of gases flared. The total efficiency increases to $64 \%$. The increased HP steam amount supplied to the power plant and the increased $\mathrm{DH}$ production from the $\mathrm{MeOH}$ synthesis results in higher condensing power production operation. 
In case $D$, hydrogen from the COG is separated by PSA. The hydrogen is blended biomass based synthesis gas. The tail gas from the PSA containing $\mathrm{CH}_{4}$ and $\mathrm{CO}$ is fired in the power plant together with the tail gas from the $\mathrm{MeOH}$ synthesis. The $\mathrm{DH}$ production from the $\mathrm{MeOH}$ synthesis and the HP steam recovered results in increased condensing power production. The corresponding total efficiency decreases to $54 \%$.

In cases B-D the total power production increases to a maximum, close to $840 \mathrm{GWh}$, resulting in limitation in the recovery of process gases. In case A there is still possibility to utilize more process gases.

Table 4. Flared gases (GWh/yr)

\begin{tabular}{|l|c|c|c|c|c|}
\hline & $\begin{array}{c}\text { Ref } \\
2006\end{array}$ & Case A & Case B & Case C & Case D \\
\hline Total & 392 & 131 & 1395 & 1160 & 1444 \\
\hline BFG & 169 & 66 & 737 & 960 & 780 \\
\hline BOFG & 157 & 55 & 546 & 55 & 546 \\
\hline COG & 67 & 10 & 111 & 145 & 118 \\
\hline
\end{tabular}

For security reasons, also COG is needed when flaring BFG and BOFG.

Table 5. Gas balance methanol production (GWh/yr)

\begin{tabular}{|l|c|c|c|c|}
\hline & Case A & Case B & Case C & Case D \\
\hline COG & 656 & 555 & 521 & 0 \\
\hline COG H2 & 0 & 0 & 0 & 176 \\
\hline BOFG & 185 & 0 & 492 & 0 \\
\hline BIOG & 0 & 2190 & 2190 & 2190 \\
\hline
\end{tabular}

Table 6. CHP operation (GWh/yr)

\begin{tabular}{|l|c|c|c|c|c|}
\hline & $\begin{array}{c}\text { Ref } \\
2006\end{array}$ & Case A & Case B & Case C & Case D \\
\hline Fuel gas & 2281 & 2126 & 1422 & 1224 & 1687 \\
\hline BFG & 1655 & 1652 & 981 & 758 & 939 \\
\hline BOFG & 389 & 306 & 0 & 0 & 0 \\
\hline COG** & 237 & 0 & 0 & 0 & $375 * *$ \\
\hline Tailgas MeOH & & 154 & 427 & 453 & 360 \\
\hline $\begin{array}{l}\text { HP steam } \\
\text { MeOH }\end{array}$ & n.a. & 104 & 534 & 602 & 450 \\
\hline DH MeOH & n.a. & 53 & 613 & 584 & 516 \\
\hline DH CHP & & 700 & 141 & 169 & 237 \\
\hline DH & & 753 & 753 & 753 & 753 \\
\hline Power BP & 331 & 326 & 128 & 148 & 160 \\
\hline Power Cond. & 272 & 335 & 713 & 693 & 681 \\
\hline Efficiency* & $50.7 \%$ & $63.7 \%$ & $58.5 \%$ & $63.9 \%$ & $54.4 \%$ \\
\hline
\end{tabular}

$*($ power $+\mathrm{DH}+\mathrm{MeOH}) /($ gasflare + gas $\mathrm{CHP}+$ gasMeOH $)$

** $\mathrm{H}_{2}$ free COG
Taking into account the amount of flared gases, the total efficiencies become $64 \%, 59 \%, 64 \%$ and $54 \%$ for Case A-D respectively.

\section{DISCUSSION}

Integration of a biorefinery with a steel mill and its offgases gives several possibilities and opportunities for adding value to the steel production with new revenues of a high value liquid methanol fuel product. However, at the same time it gives many variables and one of the distinguishing factors is to size the biorefinery, not only from a technical perspective but perhaps foremost for the economic performance and the competitiveness of the product on an emerging biofuel market. Perhaps the first criterion is the fuel availability, which at Luleå is not a limiting factor concerning biomass fuels, as the region is rich in forest fuels. Though, there is an integration on the capacity of available off-gases which then determines partly the size of both up- and downstream processes.

The second criterion is to estimate the smallest possible size - justifying integration rather than having a standalone biorefinery - and still achieve a production cost which is competitive with other biofuels - and fossil fuels. The latter because the methanol product has highest value as a blend-component in petrol and if no tax exemption will be available then the fuel will compete with fossil based methanol and petrol. This is important as the new Renewable Energy Directive from EU demands declaration on sustainability, which then gives a decision on tax exemption. The current methanol price is about $€ 320$ per ton (Methanex, Feb 2012) which translates into about 500 $\mathrm{SEK} / \mathrm{MWh}$. The value for heat is much smaller and in addition, the heat demand is perhaps also less than 5000 hours. The economic conclusion is therefore to focus on (large) methanol production.

Modern natural gas based methanol plants built today are so called mega plants with an annual output of $>1$ Mton or 2800 tonnes per day. With Case $\mathrm{C}$ and $40 \mathrm{MW}_{\text {th }}$ gas integrated with a biorefinery of $260 \mathrm{MW}_{\text {th }}$ (or $2400 \mathrm{GWh}$ per year) we get about 1000 tonnes per day. This is almost one third of today's mega plants, small but not the smallest in the park. Nevertheless, if the plant should be competitive, it should be essentially larger. On the other hand a larger plant will put strain on biomass logistics. A fuel input of $300 \mathrm{MW}_{\text {th }}$ equals 1 Mton per year of wood, a substantial amount. In the case of full tax exemption the sales value would be some 1200 SEK/MWh (including distribution cost and margins). Anyway, with such value the biorefinery would not need to be super large. However, ethanol or other similar fuel would be closest competitors and ultimately it is the production cost of modern-sized ethanol plants and the ethanol market that gives the sales cost for the methanol.

For the steel mill the closest question is the value of the gas today with combustion in the Luleå CHP for power and heat production contra production of methanol as a liquid 
motor fuel. At the same time the steam cycle of the CHP plant must be balanced against the variations in heat load to minimize need for flaring when there is no use of the offgases. In summary, there are too many variables and too little known information to make a recommendation on even close optimum values. The export of carbon in coke oven and/or BOF gas can influence the need for emission rights and the economic evaluation.

Taking it from the biomass side of $300 \mathrm{MW}_{\text {th }}$ fuel input and other studies for biorefinery production costs gives a production volume that is deemed tentatively feasible. This will give a starting point for a process that is iterative at best and also will depend on location and market.

\section{CONCLUSIONS}

Depending on the case, in the range of $98000-282000$ tons of methanol per year can be produced, where Case $C$ has the highest methanol production rate. The most beneficial from an energy efficiency point of view is case $A$ and $C$, where overall plant efficiencies of approximately $64 \%$ are obtained. This is a result of the of the HP steam recovered and utilized in the CHP steam cycle. Additionally, in Case A where no biomass synthesis gas is involved, reaches the highest methanol efficiency, above $70 \%$. From energy point of view, Case A may be considered as the most promising production case and compared to the current CHP production (reference case 2006), the overall energy efficiency increases by $13 \%$-units at the same time as 98000 tons of methanol is produced.

\section{FUTURE WORK}

It is of great importance to evaluate the economics of the methanol production. This is work in progress and the results will soon be available.

\section{ACKNOWLEDGEMENT}

The authors greatly acknowledge the financial contribution of the Swedish Energy Agency and SSAB EMEA. The authors would also like to thank Bio4Energy, a strategic research environment appointed by the Swedish government, for supporting this work.

\section{REFERENCE}

[1] Research In China. China Methanol Industry Report, 2009-2010. TCY011. Aug 2010.

[2] Lundgren J., Asp B., Larsson M., Grip C-E. Methanol production at an integrated steel mill. Proc. of the 18th International Congress of Chemical and Process Engineering, 24-28 August, 2008, Prague, Czech Republic.

[3] Larsson M., and Dahl J. 2003. Reduction of the specific energy use in an integrated steel plant: the effect of an optimisation model. I S I J International. 43, 10, pp. 16641673.

[4] Wang C., Karlsson J., Hooey L., and Bodén A., 2011, Application of oxygen enrich-ment in hot stoves and its potential influence on the energy system in an integrated steel plant, International conference of WREC 2011, May 2011, Linköping, Sweden.

[5] Ekbom, T., Brandberg, Å., Boding, H., Ahlvik, P., "BioMeeT II - Stakeholders for Biomass based Methanol/DME/Power/Heat Energy Combine", Swedish Energy Agency and European Commission, Altener II Report, Contract No. 4.1030/C/00-014, Stockholm, 2003

[6] Albertazzi, S., Basile, F., Brandin, J., Einvall, J., Fornasari, G., Hulteberg, C., Sanati, M., Trifirò, Vaccari, A. Effect of fly ash and $\mathrm{H}_{2} \mathrm{~S}$ on a Ni-based catalyst for the upgrading of a biomass-generated gas. Biomass\&Bioenergy 32 (2008) 345.

[7] Albertazzi, S., Basile, F., Brandin, J., Einvall, J., Hulteberg, C., Fornasari, G., Rosetti, V., Sanati, M., Trifirò, Vaccari, A. The technical feasibility of biomass gasification for hydrogen production. Catalysis Today 106 (2005) 297.

[8] Ertl, G., Knözinger, H., Schüth, F., Weitkamp, J., (Eds). Handbook of Heterogeneous Catalysis., 2008. John Wiley \& Sons ISBN978-3-527-31241-2.

[9] Larson ED, Consonni S, Katofsky RE, lisa K, Fredrick Jr. WJ. A Cost-Benefit Assessment of Gasification-Based Biorefining in the Kraft Pulp and Paper Industry. Princeton: Princeton Environmental Institute; 2006, 152 p. DE-FC2604NT42260

[10] Stahl, K. The Värnamo Demonstration Plant. Trelleborg: Berling Skogs; 2001. 133 p

[11] Opcon Powerbox - Emission free electric power. Opcon $A B$. [Internet] [cited: 2010 Feb 23] www.opcon.se

[12] Basu A, Gradassi M, Sills R. Use of DME as a Gas Turbine Fuel. New Orleans: ASME Turbo-Expo; 2001. ASME paper no 2001-GT-0003 